\title{
Studies on the Cu (II) and Co (II) Complexes with N,N'-bis (2-benzothiazolyl) -2,6 Pyridine Dithiocarboxamides
}

\author{
A.K. SRIVASTAVA, SWATI KUMARI and NIDHI SRIVASTAVA \\ Department of Chemistry, B. R. A. Bihar University, Muzaffarpur - 842001 India. \\ ${ }^{*}$ Corresponding author E-mail: aksrivastavaa @ rediffmail.com \\ http://dx.doi.org/10.13005/ojc/300473
}

(Received: September 18, 2014; Accepted: October 29, 2014)

\section{ABSTRACT}

The ligand N,N'-bis (2-benzothiazolyl)-2,6-pyridine dithiocarboxamides and its Cu (II) and Co (II) complexes were synthesized. Their structures were elucidated on the basis of elemental analysis, analytical data, magnetic moments, electronic spectral and IR Spectral studies. The complexes were found to be monomeric and nonelectrolytic in nature. On the basis of electronic spectral studies the complexes were concluded to be distorted octahedral. The IR Spectrum suggested that the ligand behaved as uninegative bidentate ligand coordinating through nitrogen and sulphur atoms.

Key words: N,N'-bis(2-benzothiazolyl)-2,6-pyridine dithiocarboxamide, 2,6-pyridine dithiocarboxylic acid, 2-aminobenzothiazole, spectral study,).

\section{INTRODUCTION}

The coordination chemistry of amide ligand is an important part of a number of chemical investigations. Sigel and Martin ${ }^{1}$ reviewed the structure and stability of metal ion complexes of amide, oligopeptides and related ligands. In recent years, pyridine carboxamides, a burgeoning class of multidentate ligands have received much importance because these ligands have found use in asymmetric catalysis, ${ }^{2,3}$ molecular receptors, ${ }^{4,5}$ dendrimer synthesis ${ }^{6}$. Many derivatives of pyridine dithiocarboxamides show anti inflammatory, antipyretic and analgesic activities ${ }^{7-8}$.
In this paper the synthesis of $\mathrm{N}^{\prime} \mathrm{N}^{\prime}-\mathrm{bis}(2-$ benzothiazolyl) -2,6-pyridine dithiocarboxamide(I) and isolation of their $\mathrm{Cu}(\mathrm{II})$ and $\mathrm{Co}(\mathrm{II})$ complexes are reported. The complexes were characterized using elemental analysis, magnetic moments, UV - Visible spectra and IR Spectral Studies.

\section{MATERIAL AND METHODS}

The solubility of all complexes were tested in cold and hot water, in common organic solvents and all the complexes were found to be insoluble. 
UV - Vis spectrum was recorded in solid state by diffuse reflectance method due to insoluble nature of complexes using Barium sulphate as inert material. IR spectra were obtained on Perkin Elmer 157 or 577 model in nujol mull or Potassium bromide/ Cesium iodide disc. The estimation of $\mathrm{Cu}$ and Co were carried out in our laboratory by using Vogel's method'.

\section{Synthesis of ligand BPD}

2,6 - Pyridine dithiocarboxylic acid (1.99 $\mathrm{g}, 10 \mathrm{mmol})$ and thionyl chloride $(20-25 \mathrm{ml})$ were refluxed under anhydrous conditions for 4-6 $\mathrm{h}$. The excess thionyl chloride was removed under reduced pressure and the remaining mixture was cooled at $0^{\circ} \mathrm{C}$ and dry pyridine $(30-35 \mathrm{ml})$ was added followed by 2-aminobenzothiazole $(3.0 \mathrm{~g}$, $20 \mathrm{mmol}$ ) with occasional stirring, until the evolution of $\mathrm{HCl}$ had ceased. The solid obtained was poured into ice cold water $(200 \mathrm{ml})$, filtered off and washed with $5 \% \mathrm{NaHCO}_{3}$ solution, then with hot water and ethanol. The resulted black crude product was recrystallized from dioxane. The purity of compound was checked by TLC.

\section{Synthesis of the complexes}

A solution of $5 \mathrm{mmol}$ of $\mathrm{MCl}_{2}[$ where $\mathrm{M}=\mathrm{Cu}$ (II) and Co (II) ] in ethanol (10ml) was added to the ligand $(2.31 \mathrm{~g}, 5 \mathrm{mmol})$ suspended in nitrobenzene $(10 \mathrm{ml})$ and the mixture was refluxed for $12 \mathrm{~h}$. The obtained precipitate was filtered off, washed with water and ethanol and dried in air. All the isolated complexes were insoluble in most organic solvents, but soluble in DMF and DMSO.

The complexes decompose without melting when heated above $310^{\circ} \mathrm{C}$.

\section{RESULTS AND DISCUSSION}

Elemental analysis showed that formula of ligands was $\mathrm{C}_{21} \mathrm{H}_{13} \mathrm{~N}_{5} \mathrm{~S}_{4}\left(\mathrm{H}_{2} \mathrm{~L}_{1}\right), \mathrm{C}_{23} \mathrm{H}_{17} \mathrm{~N}_{5} \mathrm{~S}_{4}\left(\mathrm{H}_{2} \mathrm{~L}_{2}\right)$ and the formula of complexes were $\mathrm{ML}_{2}$ where $\mathrm{M}=$ $\mathrm{Cu}$ (II) and Co (II) ions. The complexes were insoluble in water, benzene and other common solvents but were soluble in DMSO and DMF. The complexes were characterized by IR and UV absorption data.

\section{IR Spectra}

The infrared spectrum of the ligand showed a band around $3254 \mathrm{~cm}^{-1}$ which was assigned to $v_{\mathrm{NH}}$ vibration. The $\mathrm{N}-\mathrm{H}$ stretching appeared in all complexes as a very weak band. While $>\mathrm{C}=\mathrm{S}$ group of ligand absorbed around $1180 \mathrm{~cm}^{-1}$ and exhibited medium strong bands and $>\mathrm{C}=\mathrm{S}$ group of complexes registered a lower shift of around 25 to $27 \mathrm{~cm}^{-1}$ and appeared at $1155 \mathrm{~cm}^{-1}$ as medium band. This indicated thio enolisation of $>\mathrm{C}=\mathrm{S}$ group during the complex formation.

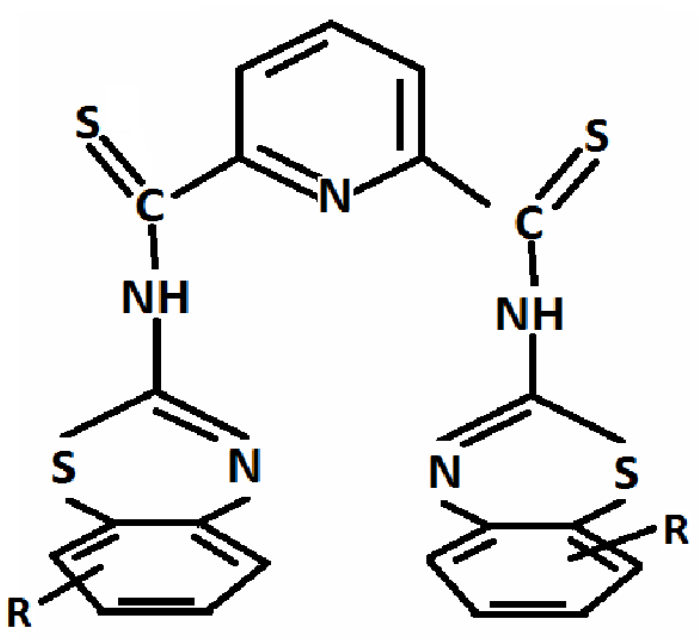

Where

$\mathrm{R}=\mathrm{H}$ for $\mathrm{H}_{2}\left(\mathrm{~L}_{1}\right)$

$R=5$-methyl for $\mathrm{H}_{2}\left(\mathrm{~L}_{2}\right)$

$R=7$-methyl for $\mathrm{H}_{2}\left(\mathrm{~L}_{3}\right)$

Fig. 1:

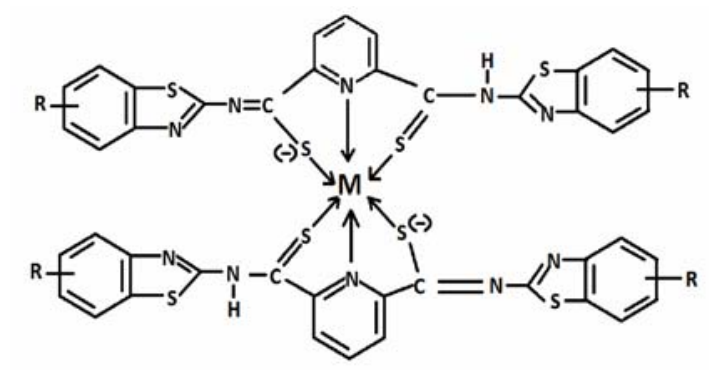

Where

$\mathrm{R}=\mathrm{H}$ for $\mathrm{H}_{2}\left(\mathrm{~L}_{1}\right)$

$\mathrm{R}=5-\mathrm{CH}_{3}$ for $\mathrm{H}_{2}\left(\mathrm{~L}_{2}\right)$

$\mathrm{R}=7-\mathrm{CH}_{3}$ for $\mathrm{H}_{2}\left(\mathrm{~L}_{3}\right)$

Fig. 2: 


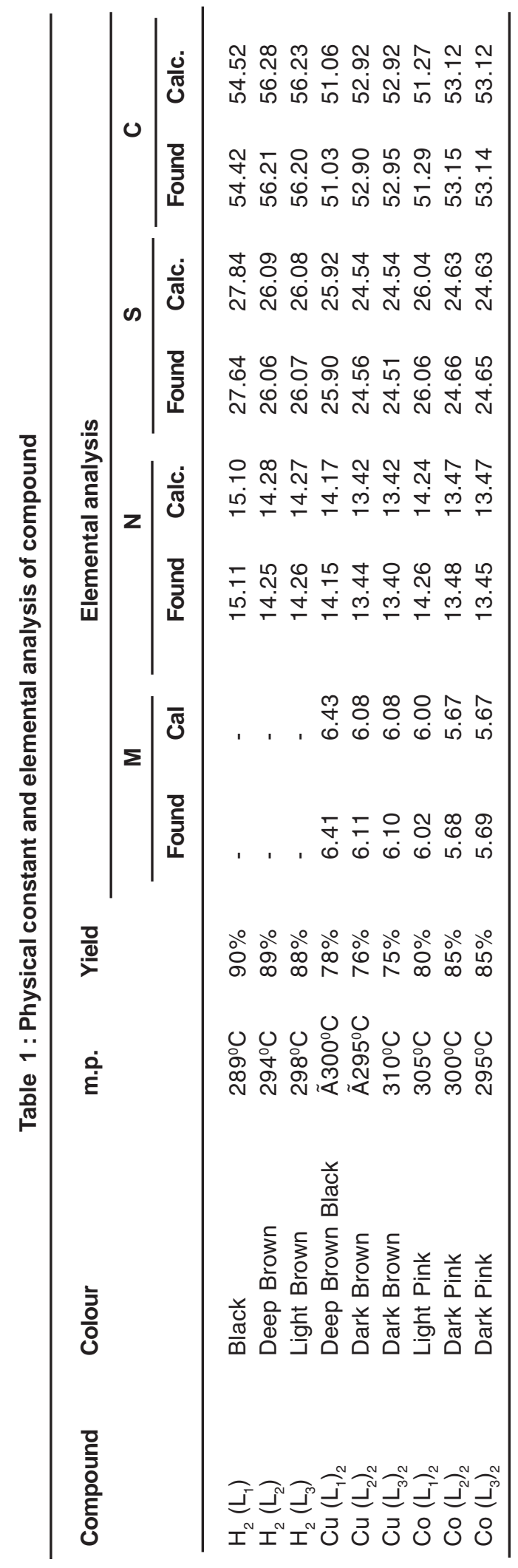

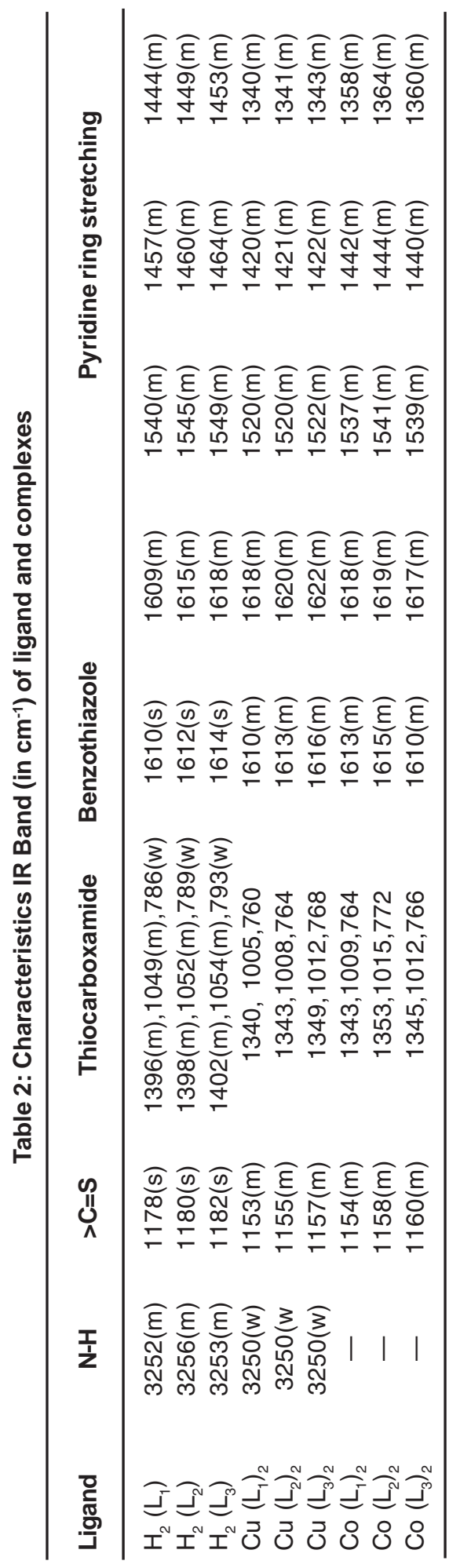


The benzothiazole absorption and pyridine ring absorption of ligand is also merged with the thio group and therefore a strong and medium absorption is displayed. The pyridine ring stretching of complexes registered a lower shift (except the first band) which indicated the involvement of $\mathrm{N}$-atom in the ring coordination.

\section{Electronic spectra}

The electronic spectral bands in ligands were obtained at around $273 \mathrm{~nm}$ and $359 \mathrm{~nm}$ which might have arose due to $\mathrm{n} \rightarrow \pi^{*}$ and $\pi \rightarrow \pi^{*}$ transitions.

The electronic spectral bands in $\mathrm{Cu}$ (II) observed around $360 \mathrm{~nm}$ appeared due to ${ }^{2} \mathrm{~B}_{1 \mathrm{~g}} \rightarrow{ }^{2} \mathrm{~B}_{2 \mathrm{~g}}$ mixed with internal ligand transition and the ${ }^{2} \mathrm{~B}_{1 \mathrm{~g}} \rightarrow{ }^{2} \mathrm{E}_{\mathrm{g}}$ transition coupled with internal ligand transition and charge transfer transition occurred at $275 \mathrm{~nm}$. The only $\mathrm{d}$-d transition of metal ion observed around $724 \mathrm{~nm}$ appeared to arise due to ${ }^{2} \mathrm{~B}_{1 \mathrm{~g}} \rightarrow{ }^{2} \mathrm{~A}_{1 \mathrm{~g}}$ transition.

In Co (II) complexes the electronic spectral bands (excluding the internal ligand transitions) were identified at around $512 \mathrm{~nm}$ and $460 \mathrm{~nm}$ and they were supposed to arise due to ${ }^{4} \mathrm{~T}_{1 \mathrm{~g}}(\mathrm{~F}) \rightarrow{ }^{4} \mathrm{~A}_{2 \mathrm{~g}}$ and ${ }^{4} \mathrm{~T}_{1 \mathrm{~g}}(\mathrm{~F}) \rightarrow{ }^{4} \mathrm{~T}_{1 \mathrm{~g}}(\mathrm{P})$ transitions of approximately high spin octahedral Co (II) geometry. The Covalent character and $10 \mathrm{Dq}$ were calculated on the basis of data ${ }^{10}$ and found as

$$
\alpha=0.95, \quad \beta^{0}=5 \%, 10 \mathrm{Dq}=13109 \mathrm{~cm}^{-1}
$$

\section{CONCLUSION}

The tentative structure of the complex, on the basis of above discussion were proposed as

\section{REFERENCES}

1. Sigel H., Martin R.B., Chem. Rev. 1982, 82, 385.

2. Conlon D.A., Yasuda N.A., Catal Synth 2001, 1, 343.

3. Trost B.M., Hachiya I., J. Am. Chem. Soc. 1998, 120, 1104

4. Collinson S.R., Gelbrick T., Hurshtouse M.B., Tusher J.H.R., Chem. Commun. 555 , 2001.

5. Huc I., Krische M.J., Funeriu D.P., Lehan J.M., Eur. J. Inorg. Chem. 1999, 1415.

6. Epperson J.D. Ming L.J., Baker G.R.,
Newkome G.R., J. Am. Chem. Soc. 2001 123, 8583.

7. Matsujaki M., Okable H., Tanaka S., Japan Kokai 1982, 77, 33676.

8. Kumar, M., Saxena, P.N., Orient J. Chem., 2012, 28(4), 1927-1931.

9. Vogel A.I., "A text book of quantitative Inorganic Analysis “ Longmans, 1964, P.P. $358-479$.

10. Lever A.B.P, J. Chem. Ed., 1968, 45(11), 711. 